Research Article: Art

\title{
Khazanah Tersembunyi yang Semakin Lenyap: Seni Ukiran Patung Kayu Suku Kaum Jah Hut
}

\author{
Nor Edzrine Abdullah Sani ${ }^{1}$, Harleny Abd Arif ${ }^{1}$ \\ ${ }^{1}$ Jabatan Seni dan Reka Bentuk. Fakulti Seni, Komputeran dan Industri Kreatif. \\ Universiti Pendidikan Sultan Idris, Malaysia.
}

Article History
Received:
26.07 .2021

Revised:

13.08.2021

Accepted:

17.08.2021

*Corresponding Author: Harleny Abd Arif

Email:

harleny@fskik.upsi.edu.my

This is an open access article, licensed under: $\mathrm{CC}-\mathrm{BY}-\mathrm{SA}$

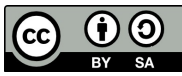

Abstrak: Ukiran patung kayu merupakan satu simbol kekuatan dalam masyarakat suku kaum Jah Hut. Suku kaum Jah Hut menjadikan ukiran patung kayu ini sebagai bahan perantaraan bagi menjalankan upacara ritual dalam kehidupan mereka suatu ketika dahulu. Kajian ini dijalankan untuk mengetahui fungsi ukiran patung kayu dalam kehidupan masyarakat Orang Asli suku kaum Jah Hut di Kg Kol, Ulu Cheka Jerantut. Manakala, objektif kajian pula adalah untuk mengenal pasti sejauh mana penghasilan ukiran patung kayu dapat direalisasikan dalam kehidupan mereka sehingga ke hari ini. Pendekatan kualitatif melalui kajian kes telah digunakan bagi menerangkan secara deskriptif budaya masyarakat Orang Asli suku kaum Jah Hut. Temu bual tidak berstruktur, pemerhatian, analisis dokumen dan rakaman visual merupakan kaedah yang telah digunakan. Berdasarkan maklumat yang diperoleh semasa kerja di lapangan, dapatan kajian mendapati corak hidup suku kaum Jah Hut adalah berpegang kepada kepercayaan, adat dan warisan. Pada masa kini masyarakat Orang Asli telah mula mengecapi arus pemodenan dalam kehidupan mereka. Seiring dengan arus pemodenan, warisan tinggalan nenek moyang mereka seharusnya tidak dilupakan. Penulisan ini adalah bertujuan untuk berkongsi pengalaman dan pengetahuan pengkaji tentang khazanah yang semakin lenyap bagi seni ukiran patung kayu kaum Jah Hut

Kata Kunci: Budaya, Jah Hut Seni, Kepercayaan, Ukiran Patung Kayu.

Disappearing Hidden Treasures: The Carving of Wooden Sculptures of the Jah Hut Tribe

Abstract: The wooden sculpture carving is a symbol of strength in the Jah Hut tribal society. The Jah Hut tribe used this wooden sculpture as an intermediate material to carry out ritual ceremonies in the past. This study was conducted to find out the function of wooden sculpture carving in the life of Orang Asli community of the Jah Hut tribe in Kg Kol, Ulu Cheka Jerantut. Meanwhile, the objective of the study is to identify how far the production of wooden sculptures can be realized in their lives to this day. A qualitative approach through case studies has been used to describe descriptively the culture of the Orang Asli community of the Jah Hut tribe. Unstructured interviews, observations, document analysis and visual recordings are the methods that have been used. Based on the information obtained during the work in the field, the findings of the study found that the lifestyle of the Jah Hut tribe is adhering to beliefs, customs and heritage. Nowadays, the Orang Asli community has begun to enjoy the current of modernization in their lives. Along with the currents of modernization, the legacy of their ancestors should not be forgotten. This writing aims to share the experience and knowledge of researchers about the disappearing treasures of the Jah Hut tribe wood sculpture art.

Keywords: Beliefs, Culture, Jah Hut, Wood Sculpture. 


\section{Pendahuluan}

Masyarakat Orang Asli dari suku kaum Jah Hut merupakan antara suku kaum yang mahir dalam penghasilan ukiran patung kayu. Ukiran patung kayu yang dihasilkan adalah ilham dari pengamatan yang diperoleh melalui persekitaran mereka dan juga dari mimpi seorang Poyang atau Bomoh. Poyang merupakan pengukir mahir dalam seni pertukangan ukiran patung kayu bagi suku kaum Jah Hut. Pelbagai ukiran patung telah dihasilkan dengan keunikannya yang tersendiri. Lazimnya, patung yang diukir akan diguna pakai dalam menjalankan upacara ritual untuk mengubati penyakit yang dihadapi oleh seseorang pesakit di kampung mereka. Menurut Rohendi \& Husain [1] bahawa karya seni tokoh tersebut dengan sendirinya merefleksikan nilai estetika dan budaya yang menjadi spiritual dan identiti dari persekitaran pada zamannya. Spritual dalam karya menampakkan diri dalam kematangan idea, ikon, media dan visualisasinya. Pada kesempatan yang ada, spiritual wujud sebgai interpretasi kualitatif terhadap sebuah karya secara objektif.

Namun pada masa kini, seni ukiran patung kayu suku kaum Jah Hut semakin lenyap mengikut arus kemodenan. Kesan dari pengaruh arus kemodenan, membuatkan generasi muda mereka semakin hari semakin sukar untuk menerima segala ilmu ukiran dari pengukir sekaligus kurang berminat untuk meneruskan warisan nenek moyangnya. Sebaliknya mereka beralih kepada tumpuan dengan mencari pekerjaan lain demi meningkatkan kelangsungan hidup. Selain itu juga kesukaran dalam mendapatkan bahan kayu serta anutan agama yang berlainan juga membuatkan ukiran patung kayu ini semakin ditinggalkan.

\section{Sorotan Kajian}

Berdasarkan dari buku terbitan Jabatan Muzium Negara menyatakan bahawa, masyarakat Orang Asli ini sememangnya kaya dengan warisan dan budayanya yang tersendiri [2] [3] [4] [5]. Setiap ukiran kayu yang diilhamkan oleh masyarakat Orang Asli ini merupakan sebahagian daripada kepercayaan animisme mereka. Setiap patung yang diukir oleh mereka melambangkan unsur-unsur yang pelbagai seperti tanah, pelangi, guruh, angin, lautan dan bumi. Dalam dunia mitologi mereka, patung-patung yang diukir mempunyai pelbagai bentuk dan fungsi serta dipercayai jelmaan roh nenek moyang mereka. Setiap apa yang dihasilkan oleh mereka adalah idea dari pemikiran mereka yang kreatif. Terjemahan gambaran yang dihasilkan itu menunjukkan keunikannya yang tersendiri. Setiap gambaran yang ada pada seni ukiran mereka turut mempunyai fungsi yang telah ditentukan oleh tukang ukir mereka.

Abd Hamid \& Lasa menyatakan bahawa sesungguhnya setiap insan tidak terkecuali daripada kemahuan seni dan penzahiran seni [6]. Penzahiran seni dijelmakan menerusi pelbagai aktiviti seni seperti dalam seni tari, seni silat, seni lakon, seni pertukangan dan pelbagai bidang seni lain. Seni mempertimbangkan nilai estetika yang bersifat universal. Nilai estetika yang subjektif mempertimbangkan keselesaan dan keharmonian pertimbangan yang sesuai dengan keperluan manusia. Hanya bakat serta naluri seni semula jadi individu itu sahaja yang menentukan sejauh mana individu itu menyedari tentang seni, terlibat dengan kegiatan seni dan mencintai seni. Keperluan kepada pemikiran berseni hadir tanpa disedari dan bukan merupakan satu paksaan pada diri seseorang. Pemikiran berseni juga dapat menyatukan fungsi seni, reka bentuk dan nilai estetik.

Begitu juga dengan kehidupan dalam golongan masyarakat Orang Asli suku kaum Jah Hut. Hasil kajian yang diperoleh menunjukkan hasil seni ukiran mereka dapat memberi suatu gambaran bahawa sesuatu karya yang dihasilkan itu adalah berkait rapat dengan kehidupan dan kegunaan harian dalam kalangan mereka. Seni kraf yang dihasilkan dalam kalangan suku kaum Jah Hut ini merupakan hasil seni yang sangat tinggi nilainya dalam konteks budaya pada suatu ketika dahulu. Sehinggakan ukiran yang dihasilkan itu, dahulunya pernah mendapat pujian para pelancong asing yang meminati seni ukiran patung kayu terhadap bakat, keunikan dan kelebihan yang dimiliki oleh masyarakat suku kaum Jah Hut ini.

Berdasarkan Seni kraf kayu Motif dan Teknik yang di terbitkan oleh Institut Kraf Negara menyatakan bahawa keindahan seni ukiran kayu di alam Melayu boleh dinilai pada kelembutan silat yang terdapat pada daun, bunga dan batang [7]. Penggunaan warna dan penyerlahan urat pada silat dapat menonjolkan ciri-ciri keindahan pada ukiran. Nilai estetika dalam sesebuah karya ukiran kayu diambil kira pada keindahan ukiran, konsep, komposisi, pemilihan bahan, teknik dan keemasan. Kemahiran pengukir, faktor alam persekitaran, bahan binaan dan kepercayaan juga mempengaruhi nilai estetik seni kraf kayu. Konsep dan olahan idea pada motif ukiran mampu menambah nilai sebuah penghasilan berseni dalam karya ukiran. 


\section{Kaedah Kajian}

Dalam kajian ini, pengkaji telah menggunakan beberapa kaedah kajian iaitu kaedah temu bual tidak berstruktur, pemerhatian, dokumentasi serta rakaman visual dan audio bagi mendapatan gambaran sebenar kehidupan masyarakat suku kaum Jah Hut.

\subsection{Kaedah Temu Bual}

Penyelidikan Kualitatif banyak bergantung kepada temu bual yang digunakan. Temu bual merupakan satu kaedah pengumpulan data yang paling biasa digunakan dalam kajian sosial [8]. Menurut Schensul temu bual tidak berstruktur atau temu bual penerokaan memerlukan minda yang peka, pemikiran yang logik serta kemahiran yang baik [9]. Menurut Rohendi \& Husain [1], temubual adalah suatu teknik yang digunakan untuk memperoleh maklumat tentang kejadianyang mana penyelidik tidak dapat mengamati sendiri secara langsung. Namun demikian, temu bual hanya akan berhasil jika seseorang yang ditemu bual bersedia dan dapat memberikan kerjasama.

Walaupun temu bual yang dijalankan ini merupakan temu bual tidak berstruktur. Pengkaji telah menggunakan keadah temu bual tidak berstruktur, tidak semestinya temu bual ini tidak memerlukan perancangan. Ini kerana pelbagai aspek seperti kefahaman bahasa, persekitaran, budaya, agama dan cara hidup perlu diambil kira dalam menjalankan temu bual ini. Temu bual tidak berstruktur biasanya di gunakan bagi mendapatkan maklumat yang mendalam berkaitan sesuatu fenomena atau isu. Ini bagi memudahkan informan dan juru bahasa yang terlibat untuk memahami setiap persoalan yang dikemukakan. Berdasarkan persekitaran informan dan juru bahasa, pengkaji juga tidak terikat dengan mana-mana soalan yang telah disediakan memandangkan responden kurang fasih dalam berbahasa Melayu. Pengkaji juga mengadakan perjumpaan berulang kali bersama informan dan juru bahasa sebagai pemudah cara antara pengkaji dan informan sehinggalah pengkaji berpuas hati terhadap maklumat yang telah dikumpul. Setiap temu bual adalah bersandarkan pada persoalan kajian sehinggalah semua persoalan kajian dapat dijawab oleh informan.

Dexter [10] menyatakan bahawa terdapat tiga pemboleh ubah dalam setiap situasi temu bual yang boleh mempengaruhi dan menentukan bentuk interaksi.

1. Personaliti dan kemahiran penemu bual

2. Sikap dan orientasi orang yang ditemu bual.

3. Adalah definisi tentang kedua-dua situasi.

\subsection{Kaedah Pemerhatian}

Pemerhatian merupakan perkara yang dilakukan setiap hari oleh manusia sama ada secara sedar ataupun tidak sedar. Pemerhatian digunakan untuk merekod tingkah laku dan interaksi responden dalam kajian yang dijalankan. Terdapat dua jenis pemerhatian iaitu pemerhatian turut serta dan pemerhatian tidak turut serta. Kaedah pemerhatian turut serta merupakan kaedah yang digunakan dalam kajian lapangan pengkaji. Pengkaji akan merekod segala keperluan penting berdasarkan apa yang diperoleh.

Menurut Othman [11], pemerhatian pada asasnya adalah bersifat naturalistik, iaitu memerhati sesuatu perkara atau fenomena yang akan berlaku dalam konteks yang sebenar. Pemerhatian ini adalah pemerhatian yang tidak terikat dengan pengukuran atau tindak balas yang ditentukan adalah lebih umum tetapi bebas untuk mencari konsep atau kategori yang bermakna kepada subjek. Pemerhatian yang dilakukan bertujuan untuk digunakan bagi mengkaji interaksi yang kompleks dalam latar sosial yang sebenar.

Menurut Rohendi \& Husain [1], pemerhatian mengungkapkan gambaran sistematik mengenai peristiwa, tingkah laku, benda atau karya yang dihasilkan dan peralatan yang digunakan. Kaedah pemerhatian juga adalah kaedah yang mengamati sesuatu, seseorang, suatu persekitaran atau situasi secara berfokus dan terperinci, dan mencatatnya secara tepat dengan beberapa cara. Kaedah pemerhatian dalam penyelidikan seni dilaksanakan untuk memperolehi data tentang karya seni dalam sesuatu kegiatan dan situasi yang relevan dengan masalah penyelidikan [12] [13].

\subsection{Kaedah Dokumentasi}

Menurut Othman [11] untuk memahami sejarah serta konteks persekitaran tempat kajian, satu daripada caranya adalah dengan mengkaji dan menganalisis dokumen dan rekod tersebut bukan sahaja mengandungi pelbagai maklumat statistik tentang pelbagai aspek kehidupan populasi yang dikaji. 
Kaedah ini juga mengandungi maklumat tentang kepercayaan, budaya serta nilai yang dimiliki dan dianuti oleh masyarakat tempat yang dikaji.

\subsubsection{Kaedah Penyelidikan Perpustakaan}

Pengkaji telah membuat rujukan di Perpustakaan Negara, Perpustaakaan Muzium Negara, Perpustakaan Orang Asli Gombak serta beberapa perpustakaan awam yang lain bagi mendapatkan maklumat tambhan tentang gaya hidup masyarakat Orang asli suku kaum Jah Hut. Maklumat yang diperoleh ini bertujuan untuk menyokong segala dapatkan serta persoalan kajian yang dikemukakan [14]. Bahan rujukan yang digunakan oleh pengkaji terdiri daripada buku ilmiah yang berkaiatan, jurnal dan juga artikel.

\subsubsection{Kaedah Menerusi Internet}

Pengkaji turut mencari maklumat menerusi laman sesawang yang berkaiatan bagi menyokong datadata yang diperlukan.

\subsubsection{Rakaman Visual dan Audio}

Pengkaji telah menggunakan rakaman visual dan audio dalam kajian yang dijalankan. Rakaman visual dan audio yang digunakan ini dapat merakamkan sesuatu objek atau keadaan kajian bagi mengukuhkan lagi kesahihan data dalam setiap bahan yang diperoleh sama ada menerusi temu bual dan pemerhatian yang dijalankan.

\section{Dapatan Kajian}

Penghasilan ukiran patung kayu dalam kehidupan masyarakat suku kaum Jah Hut suatu ketika dahulu merupakan hasil kraf tangan yang sangat mempengaruhi kehidupan mereka. Informan yang terlibat terdiri daripada mereka yang mahir dan berpengetahuan dalam penghasilan seni ukiran patung kayu. Kaedah temu bual tidak berstruktur telah digunakan untuk memperoleh data dan maklumat yang bersesuaian bersama pengukir mahir yang terlibat. Kaedah pemerhatian digunakan bagi melihat sendiri setiap aktiviti yang berlaku dalam penghasilan ukiran patung kayu serta aktiviti lain yang terdapat di kampung tersebut. Corak kehidupan masyarakat Orang Asli suku kaum Jah Hut ini mempengaruhi segala aktiviti pengukiran yang dihasilkan. Rakaman visual merupakan proses yang relevan dalam memperoleh maklumat yang berkaitan selain menggunakan analisis dokumen. Analisis dokumen merupakan petunjuk yang dapat memberikan maklumat yang terperinci dalam mendapatkan bukti yang sahih sewaktu kajian lapangan dijalankan.

\subsection{Masyarakat Suku Kaum Jah Hut}

Abdullah [15] menyatakan bahawa masyarakat pribumi atau Orang Asli merupakan penghubung kepada sejarah dan tamadun awal di negara kita. Sejarah negara telah mencatatkan bahawa negara kita pernah diduduki oleh manusia sejak zaman-berzaman. Masyarakat Orang Asli, terdiri daripada tiga kelompok bangsa iaitu Negrito, Senoi dan Melayu-Proto. Senoi merupakan kelompok Orang Asli yang terbesar populasinya di Semenanjung Malaysia. Istilah Senoi berasal dari perkataan "Temiar" yang bermaksud manusia [16].

Dalam masyarakat Orang Asli perkara yang berkaitan dengan kehidupan mereka adalah hasil dari pemerhatian alam sekeliling. Kebiasaannya, setiap perkara yang berlaku dalam kehidupan mereka akan terus dikekalkan dalam menjalani kehidupan seharian. Begitu juga dengan kehidupan kaum Jah Hut yang boleh dikaitkan dengan suatu proses seumur hidup. Proses ini menggambarkan bagaimana seseorang individu dalam masyarakat Orang Asli suku kaum Jah Hut itu mempelajari kebiasaan (rutin hidup atau tingkah laku) yang meliputi cara hidup, nilai-nilai dan norma-norma yang terdapat dalam sesebuah masyarakat agar dapat diterima dalam kelompok mereka [17]. Dari aspek penempatan suku kaum Jah Hut, mereka mendiami serta mendirikan rumah di kawasan yang berhampiran dengan sungai dan hutan. Atas kebertanggungjawaban pihak kerajaan, masyarakat suku kaum Jah Hut pada masa kini dapat menikmati kemudahan dan infrastruktur yang disediakan di kawasan mereka.

Setiap suku kaum Orang Asli mempunyai beberapa kumpulan etnik yang berbeza corak hidup yang diamalkan. Begitu juga dengan kehidupan suku kaum Jah Hut yang mempunyai kumpulan tersendiri iaitu tergolong dalam kumpulan Orang Asli Senoi. Selain daripada memburu binatang dan berladang, masyarakat suku kaum Jah Hut menyara kehidupan dengan mencari rotan dan damar untuk dijual. Dari sudut kepercayaan mereka, suku kaum Jah Hut merupakan pengamal animisme 
yang menganggapkan bahawa setiap benda atau perkara yang ada di sekeliling mereka mempunyai semangat (roh) dan juga penunggu. Mereka turut mempercayai kuasa ghaib, hantu dan syaitan. Maka, dengan ini lahirlah pelbagai adat istiadat dan amalan hidup yang berlandaskan kepada kepercayaan tersebut [2].

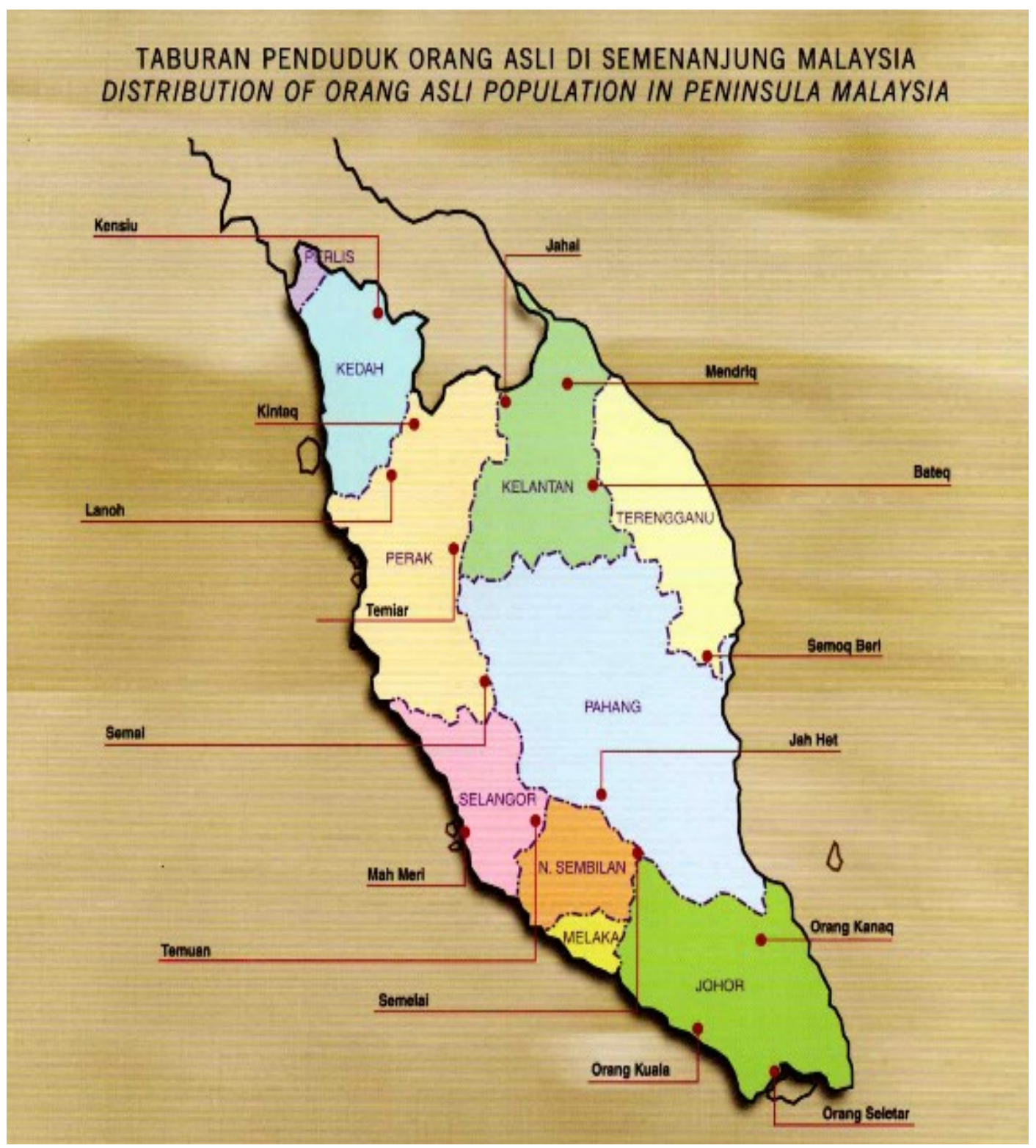

Rajah 1. Taburan Penduduk Orang Asli di Malaysia [2]

Dalam kehidupan masyarakat Orang Asli, seni sememangnya wujud sejak dari nenek moyang mereka lagi. Ini dapat dilihat dengan adanya pelbagai barangan kraf yang telah dihasilkan serta diguna pakai dalam pelbagai majlis yang dijalankan. Sememangnya, suku kaum Jah Hut ini mahir dalam penghasilan ukiran patung kayu selain dari suku kaum Mah Meri. Masyarakat suku kaum Jah Hut juga mempunyai kreativiti dan nilai yang tersendiri dalam menjalani kehidupan mereka. Malangnya, kaum Jah Hut ini kurang dikenali jika dibandingkan dengan Kaum Mah Meri [18]. Kehidupan Mah Meri yang semakin menonjol dan pandai mengambil peluang menjadikan mereka lebih dikenali [19]. 
Jadual 1. Kelompok Masyarakat Orang Asli di Malaysia [2]

\begin{tabular}{c|c|c}
\hline Negrito & Senoi & Melayu-Proto \\
\hline Kintak & Semai & Temuan \\
\hline Kensiu & Temiar & Semelai \\
\hline Menriq & Jah Hut & Jakun \\
\hline Bateq & Che Wong & Orang Kanaq \\
\hline Lanoh & Semoq Beri & Orang Seletar \\
\hline Jahai & Mah Meri & Orang Kuala \\
\hline
\end{tabular}

\subsection{Fungsi Ukiran Patung Kayu dalam Kehidupan Suku Kaum Jah Hut}

Pengkaji dapat melihat sendiri pembuatan pengukiran patung kayu ini melalui kaedah temu bual tidak berstruktur, pemerhatian dan rakaman visual di perkampungan Ulu Cheka Jerantut. Aktiviti harian yang dijalankan oleh mereka sememangnya mempengaruhi kepercayaan, adat resam dan juga kesenian yang mereka warisi. Karya-karya yang dihasilkan mereka sepenuhnya bersandarkan kepada alam persekitaran yang dilihat sendiri. Setiap hasil ukiran patung ini membawa maksud tertentu mengikut kegunaannya pada ketika dahulu. Ukiran patung kayu yang dihasilkan sememangnya unik dan tidak terjangkau di fikiran kita. Setiap penghasilannya membawa maksud yang tersendiri dengan kegunaannya yang tertentu dalam kehidupan masyarakat suku kaum Jah Hut.

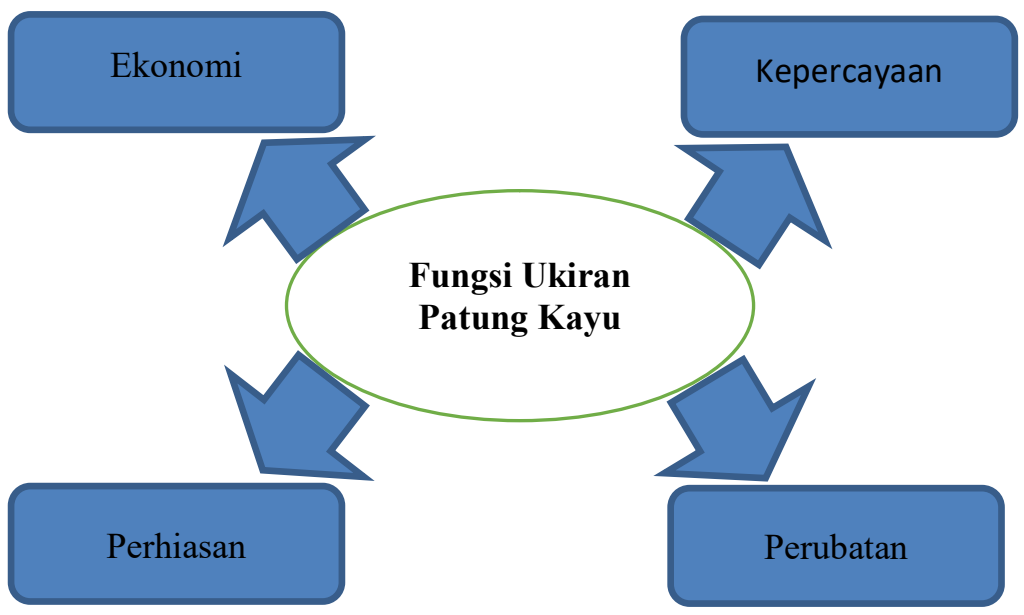

Rajah 2. Fungsi Ukiran Patung Kayu Suku Kaum Jah Hut

Dari sudut kepercayaan, berdasarkan teks rujukan Asli [17], suku kaum Jah Hut merupakan pengamal animisme dan mempercayai bahawa setiap benda di dunia ini mempunyai semangat atau penunggunya. Suku kaum Jah Hut sememangnya mempercayai tentang kehidupan di alam ghaib, hantu dan syaitan. Ukiran-ukiran yang dihasilkan mempunyai kaitan dengan kepercayaan mereka. Ukiran-ukiran ini digunakan sebagai alat dalam perubatan yang dijalankan. Patung-patung kayu yang diukir adalah berpandukan kepada penyakit yang dihadapi oleh seseorang pesakit melalui mimpi Poyang. Ketika dahulu, Poyang atau bomoh merupakan pengukir yang sangat berpengaruh dalam masyarakat suku kaum Jah Hut. Poyang akan mengetuai setiap acara ritual atau upacara kepercayaan 
dan perubatan yang dijalankan. Poyang juga akan menafsirkan segala mimpi yang diperoleh. Seterusnya, menzahirkan mimpi itu ke atas bongkah kayu bagi mendapatkan gambaran penyakit yang perlu diubati. Ukiran patung kayu yang telah siap diukir ini akan dijampi untuk mengubati segala penyakit yang dialami oleh pesakit. Setiap ukiran patung yang telah dijampi ini tidak akan di simpan oleh pesakit atau Poyang sebaliknya akan dibuang terus ke dalam hutan atau jauh dari perkampungan agar penyakit tersebut hilang dan tidak akan berjangkit kepada penduduk kampung yang lain. Pesakit juga akan berpantang selama tiga hari. Sehelai daun hijau akan digantung di hadapan pintu rumah sebagai tanda bahawa seseorang atau sesebuah keluarga itu dalam tempoh pantang berubat.

Menurut Werner [20], Orang Asli mempunyai kepercayaan yang tinggi dan mempunyai keupayaan yang luar biasa dalam mencegah dan mengubati penyakit. Pertama kalinya satu upacara kesenian menyuci telah dilakukan oleh bomoh Mah Meri yang lengkap dengan ilustrasi objek rahsia seperti Sembuang (semangat dulang), Ancak (semangat bakul) Balai (semangat rumah) dan Sampan (semangat perahu) turut menyampaikan koleksi lengkap itu Sepili (ada kisah di sebalik nama Sepili), upacara angka-angka kayu yang berfungsi sebagai pengangkut rohani untuk membuang penyakit jauh dari sakit seperti yang digunakan oleh poyang Jah Hut. Ia turut melibatkan doa dan dikir menyeluruh.

Kelompok Masyarakat Jah Hut ini turut dikenali dengan kemahiran dalam pengukiran kayu. Secara tidak langsung kemahiran yang dimiliki ini telah menjadi sumber pendapatan dalam kelangsungan hidup pengukir yang terlibat. Walau bagaimanapun, sumber pendapatan pada keluarga merupakan satu lanjutan untuk kepercayaan dan keagamaan mereka. Di samping itu, masyarakat Jah Hut jua mempercayai bahawa semangat baik dan semangat jahat akan menyelubungi setiap kehidupan seharian terutamanya kepada seseorang pesakit yang menerima gangguan syaitan atau jin. Di sini, poyang atau bomoh akan memainkan peranan mereka untuk membantu mengubati penyakit yang ada pada seseorang pesakit. Dengan terhasilnya ukiran patung ini, upacara mengubati penyakit akan berlangsung mengikut kepercayaan yang telah mereka amalkan.

\subsubsection{Ekonomi}

Sumber ekonomi merupakan salah satu penyumbang kepada hasil seni ukiran patung kayu berkembang suatu ketika dahulu. Permintaan yang tinggi membuatkan ukiran patung kayu ini mendapat sambutan. Setelah sekian lama pengukiran patung kayu ini digunakan dalam masyarakat suku kaum Jah Hut, ia mula mendapat tempat dalam kalangan pelancong asing yang datang kepada mereka. Ukiran patung yang diukir juga sering kali menerima tempahan dari jabatan-jabatan dan agensi-agensi kerajaan untuk dijadikan bahan pameran. Pameran yang dianjurkan bertujuan untuk memberikan pendedahan kepada masyarakat luar mengenai kesenian dan kebudayaan masyarakat Orang Asli yang ada. Ini merupakan saluran kepada mereka untuk memperoleh sumber pendapatan tambahan selain dari kerja-kerja kampung yang mereka jalankan.

Selain dari ukiran patung kayu, kaum Jah Hut turut menghasilkan ukiran pada kayu kubur atau dipanggil dengan galang kubur.
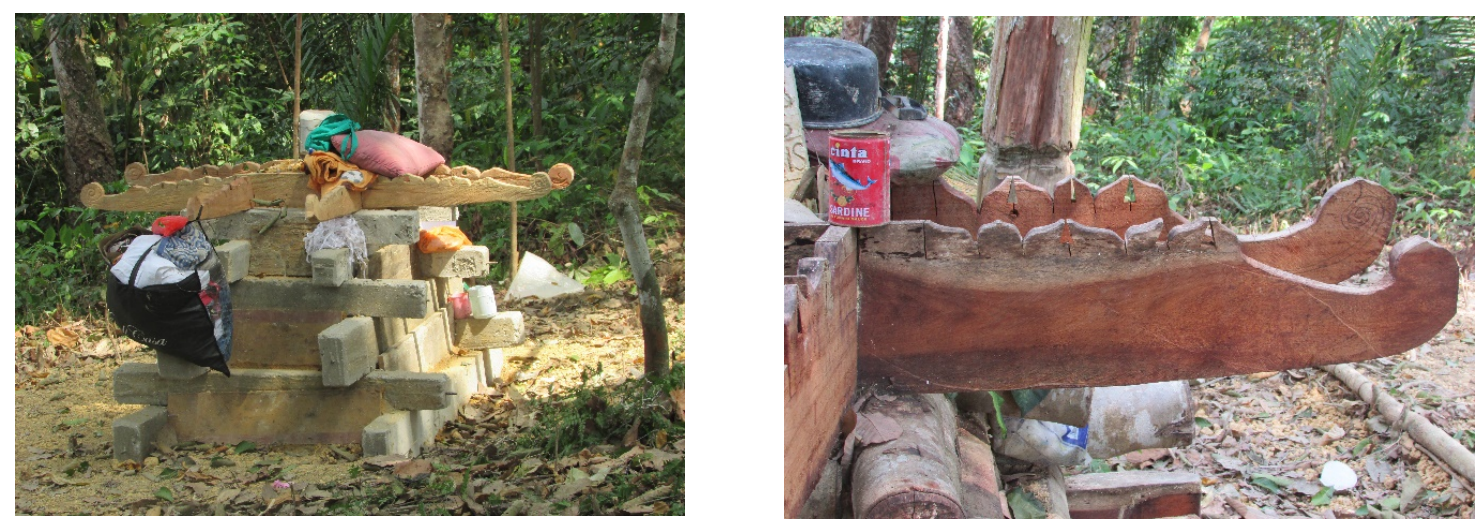

Rajah 3. Contoh Galang Kubur yang Diukir 
Galang kubur ini merupakan tanda kubur untuk si mati. Lazimnya struktur kubur ini mempunyai lima tingkat yang berbentuk piramid. Setiap penjuru akan diukir dengan pelbagai bentuk ukiran mengikut permintaan keluarga si mati atau pengukir sendiri. Lazimnya, kubur lelaki berbentuk silinder dan kubur perempuan berbentuk hiasan mendatar. Ukiran-ukiran ini akan ditempah mengikut kemahuan keluarga si mati.

\subsubsection{Perhiasan}

Dalam pada itu juga, ukiran yang dihasilkan oleh mereka telah mula dijadikan bahan hiasan. Ukiran yang dihasilkan tidak tertumpu hanya kepada ukiran patung kayu sahaja malahan mereka turut menghasilkan pelbagai bentuk untuk hiasan. Antara hiasan yang sering dihasilkan adalah seperti bekas bunga, bentuk haiwan, kayu hanyut yang diukir mengikut pengamatan yang diperoleh dan sebagainya. Semua ini telah dijadikan sebagai bahan hiasan sekaligus dijadikan sumber pendapatan dalam kehidupan mereka.
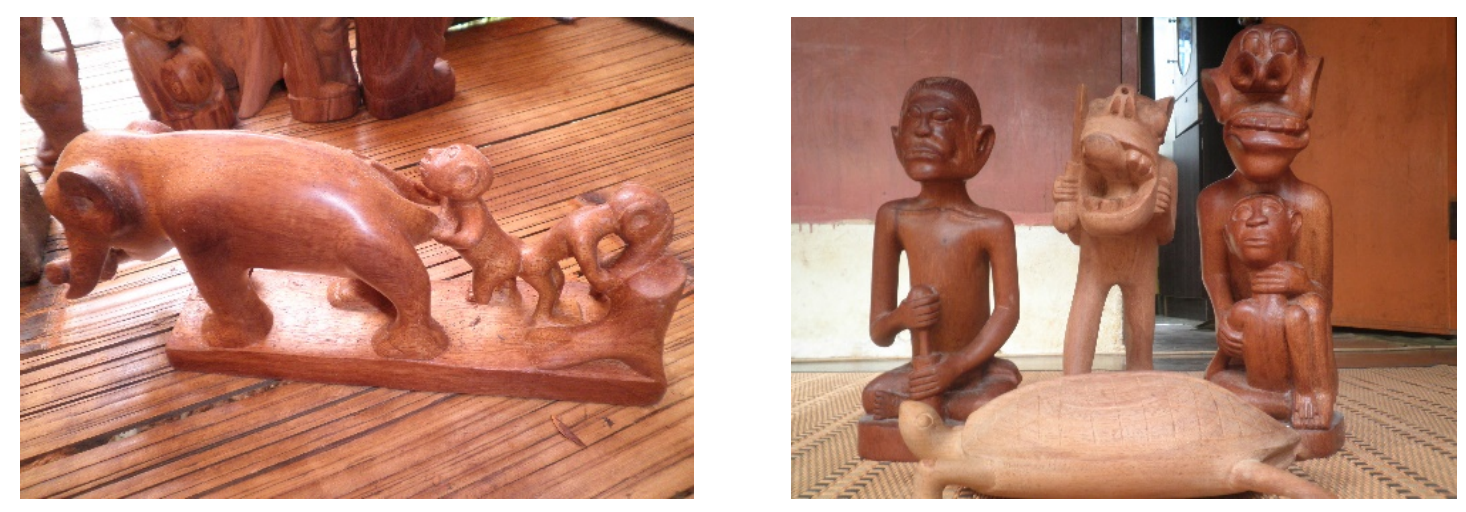

Rajah 4. Contoh Ukiran yang Dihasilkan Untuk Hiasan

Ukiran yang dihasilkan oleh kaum Jah Hut ini merupakan satu keunikan yang luar biasa bagi masyarakat luar yang melihat dan menyukainya. Setiap ukiran hanya diukir menggunakan perkakas tangan tanpa mesin. Hasil yang diperoleh sangat luar biasa. Nilai estetikanya yang tersendiri membuatkan ukiran patung yang dihasilkan pernah menjadi kebanggaan dalam masyarakat mereka suatu ketika dahulu dan diketengahkan sehingga dikenali oleh pelancong asing.

\subsubsection{Kepercayaan}

Menurut Seong [21] bahawa masyarakat Jah Hut mengamalkan kepercayaan animisme yang mempercayai setiap tempat di muka bumi ini mempunyai semangat. Antara semangat-semangat yang mempengaruhi kehidupan mereka adalah:

1. Semangat Orang : Semangat yang mengawal diri seseorang sama ada kearah kebaikan atau kejahatan.

2. Semangat Angin : Semangat yang mahukan kebebasan (mengawal nafsu).

3. Semangat Hantu (Rohani) : Mengawal diri seseorang dari takutkan hantu

4. Semangat Rusa : Semangat yang menimbul rasa berani sewaktu malam. Kaum Jah Hut percaya orang yang telah mati, rohnya akan menjadi rusa.

5. Semangat Babi (fizikal) : Semangat keberanian. Mereka yang mempunyai semangat ini tidak sesuai untuk bercucuk tanam.

6. Semangat Lalat

: Semangat berani pada waktu siang. Pasangan suami isteri mati secara berasingan tetapi akan kembali bersama.

7. Semangat Iblis

: Semangat yang mendorong manusia untuk melakukan kejahatan. Tanda-tanda yang menunjukkan seseorang itu mempunyai semangat iblis ialah iri hati, berpura-pura niat yang jahat dan sebagainya. 


\subsubsection{Perubatan}

Seong [21] turut menyatakan bahawa Benisoy merupakan upacara perubatan yang dijalankan dalam kalangan masyarakat suku kaum Jah Hut. Terdapat tiga jenis upacara Benisoy iaitu:

1. Benisoy Gelap (Benisoy Bes)

2. Benisoy Berubat

3. Benisoy datuk Nenek/Nenek Moyang

Ketiga-tiga upacara ini merangkumi upacara pemujaan yang diiringi dengan jampi dan objek pemujaan. Benisoy turut diselitkan dengan pelbagai nyanyian yang berunsurkan pemujaan. Upacara Benisoy ini diadakan selama dua hingga tiga malam berturut-turut. Sewaktu perubatan ini berjalan, ukiran patung yang diukir Poyang akan menjadi perantaraan antara poyang dan roh yang diseru. Ukiran yang dihasilkan adalah bergantung pada penyakit yang akan diubati oleh poyang. Segalanya akan tergambar pada ukiran yang diukir.

\section{Perbincangan dan Cadangan}

Malaysia kaya dengan khazanah dan warisan budaya. Namun dengan landskap kehidupan moden pada masa kini membuatkan segala karya seni dan tinggalan warisan mula dilupakan. Semua pihak seharusnya memainkan peranan yang penting dalam mengekalkan seni dan warisan yang ada. Kepentingan pengetahuan dalam seni dan warisan dapat membantu merealisasikan kehidupan sesuatu masyarakat agar menjadi lebih sempurna. Begitu juga dengan seni ukiran patung kayu dalam suku kaum Jah Hut yang sememangnya mempunyai nilai estetika yang tersendiri. Penghasilan yang dilakukan oleh suku kaum Jah Hut mempunyai identiti yang melambangkan kehidupan mereka sejak dari dahulu hingga sekarang. Kehidupan yang bergantung kepada kepercayaan dan perkara-perkara mistik atau supernaturel membuatkan mereka selesa dengan apa yang telah diharungi dalam kehidupan sejak dari turun temurun. Dari aspek nilai estetik, ukiran 3 dimensi yang dihasilkan oleh suku kaum Jah Hut ini jelas menunjukkan bahawa ukiran patung kayu yang dihasilkan mempunyai kepercayaan dan semangat dalam kehidupan mereka. Motif atau rupa bentuk yang dihasilkan adalah dari pengamatan pengukir sendiri. Pembuatan secara manual membuktikan kemahiran yang ada dalam kalangan mereka sangatlah tinggi dan harus diberikan penghormatan bagi mengekalkan seni warisan ini.

Tapi kini, generasi baru masyarakat suku kaum Jah Hut ini telah mula berubah. Kehidupan moden dan terjamin membuatkan generasi muda terus lupa untuk mendalami segala warisan, kesenian dan kepercayaan yang ada. Pegangan agama yang berbeza dan keperluan hidup antara faktor penyumbang utama seni dan warisan yang ada dalam masyarakat Jah Hut semakin dilupakan.

Cadangan yang dinyatakan ini bertujuan untuk meningkatkan tahap kesedaran terhadap kesenian ukiran kayu yang ada dalam masyarakat suku kaum Jah Hut serta dapat memberi pengetahuan kepada orang ramai.

1. Menubuhkan badan-badan atau persatuan tertentu dalam penjagaan seni warisan agar dapat memelihara kelestarian seni ukiran kayu. Selain itu juga badan-badan ini bertujuan memantau dan membantu masyarakat orang Asli dalam mempelbagaikan reka bentuk ukiran agar sentiasa tampak eksklusif mengikut peredaran zaman.

2. Memberi pendedahan dan pengetahuan kepada masyarakat luar tentang keunikan dan keistimewaan seni ukiran kayu suku Kaum Jah Hut.

3. Generasi muda suku kaum Jah Hut seharusnya berani menyahut cabaran dalam mengetengahakan seni warisan ini.

4. Mewujudkan satu jaringan pemasaran untuk memudahkan kaum Jah Hut memasarkan produk-produk kesenian mereka pada masyarakat dalam dan luar negara.

5. Secara tidak langsung kajian ini membantu generasi baru dalam mengkaji lebih mendalam seni ukiran kayu yang tinggal.

\section{Kesimpulan}

Kesimpulannya, Seni ukiran patung kayu suku kaum Jah Hut ini semakin lenyap. Pelbagai faktor telah mmpengaruhi ukiran patung kayu ini untuk terus bertahan jika langkah-langkah pengekalan tidak diambil dari sekarang. Nescaya suatu masa nanti, seni ukiran patung kayu ini mungkan akan hilang begitu sahaja. Suku kaum Jah Hut dan agensi-agensi yang terlibat seharusnya memainkan peranan yang berterusan dalam mengekalkan kesenian yang ada. Melalui hasil dapatan mendapati 
fungsi ukiran patung kayu memainkan peranan dalam kehidupan masyarakat suku kaum Jah Hut pada masa dahulu (anutan animisme). Setiap fungsi yang dinyatakan mempunyai perkaitan ukiran patung kayu dalam kehidupan masyarakat mereka.Bagi mengekalkan kesenian warisan ini, penghasilan ukiran patung kayu yang lebih bersifat kontemporari perlu diperkenalkan tanpa menghilangkan nilai estetika dan keaslian seni ukiran patung kayu yang ada dalam masyarakat mereka.

\section{Rujukan}

[1] T. R. Rohendi, dan A. H. Husain, Metodologi Penyelidikan Seni (Cetakan Pe). Tanjong Malim, Perak: Malim Sarjana, 2015.

[2] A. Haji Taha, Orang Asli: Khazanah Tersembunyi. Kuala Lumpur: Jabatan Muzium Malaysia, 2006.

[3] C. Nicholas, Orang Asli: Rights, Problems, Solutions. Subang Jaya. Malaysia Center for Orang Asli Concerns, 2010.

[4] Jebatan Hal Ehwal Orang Asli. Padanan Bahasa Melayu, Semai, Termiar. Kuala Lumpur: Bahagian Penyelidikan dan Penerangan (JHOEA), 2001.

[5] D. Holaday, C. W. Pin, and T. B. Siong. Batin Long Bin Hok's 'Bés Hyang Dnèy and Other Jah Hut Stories. (Revision of 1985). Subang Jaya: Centre for Orang Asli Concerns, 2003.

[6] M. J. Abd Hamid and H. Lasa, Estetika Seni Visual (Cetakan Pertama). Tanjong Malim, Perak: Universiti Pendidikan Sultan Idris, 2013.

[7] Institut Kraf Negara. Seni Kraf Kayu Motif \& Teknik, Rawang Selangor: Perbadanan Kemajuan Kraftangan Malaysia Kementerian Perrpaduan, Kebudayaan, Kesenian Malaysia, 2009.

[8] J. Ritchie, and J. Lewis, Qualitative Research Practice: A Guide for Social Science Students and Researchers. London: Sage Publications, 2003.

[9] L. S. Schensul, J. J. Schensul, M. D. LeCompte, Essential Ethnographic Methods: Observations, Interviews, and Questionnaires. Rowman Altamira, 1999.

[10] L. A. Dexter, Elite and specialized interviewing. UK: ECPR Press, 2006.

[11] L. Othman, Penyelidikan Kualitatif: Pengenalan kepada Teori dan Metod. Tanjung Malim Perak: Universiti Pendidikan Sultan Idris, 2014.

[12] H. Martyn and A. Paul. Ethnography: Principles in Practice, 3rd ed. London \& New York: Routledge, 2007

[13] J. Van Maanen, Tales of the Field: On Writing Ethnography. Chicago, IL: University of Chicago, 1988.

[14] Y. Xiao, and M. Watson, "Guidance on Conducting a Systematic Literature Review," Journal of Planning Education and Research, vol. 39, no. 1, pp. 93-112, 2017.

[15] M. A. Abdullah, Kenali Kami: Masyarakat Orang Asli di Malaysia. Johor: KUiTTHO, 2003.

[16] B. S. Nowak, "Ethnicity and Identity in the Malay Peninsula Based on Btsisi' Folklore and Ethnohistory," Asian Folklore Studies, vol. 63, pp. 303-323, 2004.

[17] J. H. E. O. Asli, Kehidupan, Budaya dan Pantang Larang Orang Asli. Kuala Lumpur: Kementerian Pembangunan Luar Bandar, 2002.

[18] R. Idrus, "The Discourse of Protection and the Orang Asli in Malaysia," Kajian Malaysia, vol. 29, no.1, pp. 53-74, 2011.

[19] F. S. Wardhana, X. Yuhan, and C. Qian, A Study of Cultural Identity, Cultural Heritage and Tourism Development in Mah Meri Community Cultural Village, Carey Island, Selangor, Malaysia. Kuala Lumpur: UM, 2014.

[20] R. Werner, Bomoh-Poyang: Traditional Medicine and Ceremonial Art of the Aborigines of Malaysia. Kuala Lumpur: University of Malaya, 1986.

[21] T. B. Seong, "Bes Hyang Dney: A Jah Hut Myth of Peninsula Malaysia," Journal of the Malaysian Branch of the Royal Asiatic Society, vol. 59, no. 2, pp. 139-144, 1986. 